\title{
Immune Response Model for Government-Invested Large Projects Risks
}

\author{
Yunfei Hou ${ }^{1,2}$, Yingying $\mathrm{Guo}^{3}$ and Wanwan Zhang ${ }^{3, *}$ \\ ${ }^{1}$ Wuhan University of Technology, Wuhan, P. R. China \\ ${ }^{2}$ Changsha University of Science \& Technology, Changsha, P. R. China \\ ${ }^{3}$ Zhongnan University of Economics and Law, Wuhan, P. R. China \\ ${ }^{*}$ Corresponding author
}

\begin{abstract}
Government-Invested large projects are inevitably exposed to various risks. These risks threaten the operation of projects and need to be eliminated timely. Based on the biological immune system, this paper proposes the immune response model to decrease risks in the target project. The innate immune response model responds to the regular innate risk. CBR (CaseBased Reasoning) method is used to select the most similar project. Its strategies are directly adopted to fend off the innate risk. The adaptive immune response model reduces the adaptive risk. The TOPSIS (Technique for Order Preference by Similarity to Ideal Solution) ranks the reference projects. The strategies from the top-ranking project are modified to form the final safety scheme. To test the effectiveness of this mechanism, we use the two models to solve the risk existing in Yiyang-Loudi Highway Project. The successful application indicates the feasibility of immune response model. Finally, suggestions for further research are presented in this paper.
\end{abstract}

Keywords-government-invested large projects; biological immune system; immune response model; CBR; TOPSIS

\section{INTRODUCTION}

In recent years, many cities have developed large projects to achieve economic growth. However, various risks may disturb the normal operation of projects and create massive losses. Therefore, the approach to eliminating risk is of great importance in project management. This paper proposed the immune response mechanism and built two models to help managers reduce projects risks.

Many researchers concentrate on the identification and assessment of projects risks. For example, Eybpoosh et al. (2011) used structural equation modeling (SEM) techniques to identify risk paths. Hamzaoui et al. (2015) proposed an evolutionary vision of Risk Breakdown Structure (RBS) to facilitate the identification and analysis process. Ebrat and Ghodsi (2014) built the Adaptive Neuro-Fuzzy Inference System (ANFIS) to assess construction projects risks. The fuzzy synthetic evaluation is also applied to calculate the likelihood, magnitude, and criticality of risk factor (Zhao et al., 2016). These studies assist projects managers to discriminate and qualify different risks.

In the field of risk management, Kwan and Leung (2011) provided a management method concerning risk dependency issues. Some researchers suggested that risk management plans should be customized at the outset and based on different categories of projects (Yim et al., 2015). However, some risks are uncertain and complex in reality, which requires flexible management (Geraldi, 2008). Researchers have been exploring practical management frameworks which combine the rigid control and flexible adjustment. (e.g Lenfle and Loch, 2010; Koppenjan et al., 2011).

In terms of decision-making theories, Rao and Schoenherr (2011) presented a framework for risk assessment and management, offering decision support for managers. Fang and Marle (2012) performed a decision support system (DSS) for management of project risks. Osipova and Eriksson (2013) investigated how mechanistic and organic management systems influenced the joint risk management (JRM). These methods are aimed at enhancing the management efficiency.

Despite the above research, there is still lack of an integrated risk response system for risk management. To fulfill the gap, this paper proposes the immune model for government-Invested large projects. The principles of the biological immune system are extended to risk response. The immune model imitates the complete defend mechanism of organic bodies. It can identify different risks and respond to them in different modes systematically and completely.

The remainder of this paper is organized as follows. Section 2 elaborates the immune response mechanism for governmentinvested large projects risks. In Section 3, the innate immune response model is explained. Section 4 presents the adaptive immune response model. Section 5 provides an application of the models. Finally, conclusions are offered in Section 6.

\section{IMMUNE RESPONSE MECHANISM FOR GOVERNMENT- INVESTED LARGE PROJECTS RISKS}

Government-invested large projects are unavoidably exposed to various risks. Risk response of projects is similar to the biological immune system. The organic bodies recognize viruses first and select suitable modes to kill viruses. Innate immune response reduces the common viruses and memory cells secrete antibodies, while adaptive immune response deals with the special viruses, with effective $\mathrm{T}$ cells generating antibodies. This paper applies the principles of immunity to the management of projects risk response. Table 1 gives the comparison of terms of biologic immunity and risk immunity. The concepts in organic bodies are transferred to be terms of risk management accordingly. 
TABLE I. TERMS OF BIOLOGIC IMMUNITY AND RISK IMMUNITY

\begin{tabular}{cc}
\hline Biological immune response & Risk immune response \\
\hline Antigen & Risk \\
Antigen recognition & Risk recognition \\
Lymphocyte & Risk object \\
Proliferation and activation of \\
lymphocyte \\
Antibody \\
Immunological effect
\end{tabular}

The immunity for risk comprises of risk recognition and risk response. Figure 1 demonstrates the risk immune process. In the risk recognition, risk factors are categorized into internal risk and external risk. Internal risk can be easily decreased by the design of projects. However, external risk needs a second recognition and special treatment. Because immune system only responds to risk whose influence exceeds the threshold, the risk which cannot trigger an immune response is regarded as the fake risk. Selected target risk indicators are divided into innate factors and adaptive factors. Accordingly, innate immune model eliminates innate factors and adaptive immune model reduces adaptive factors. Finally, the risk immune response ends until all the target risk vanishes.

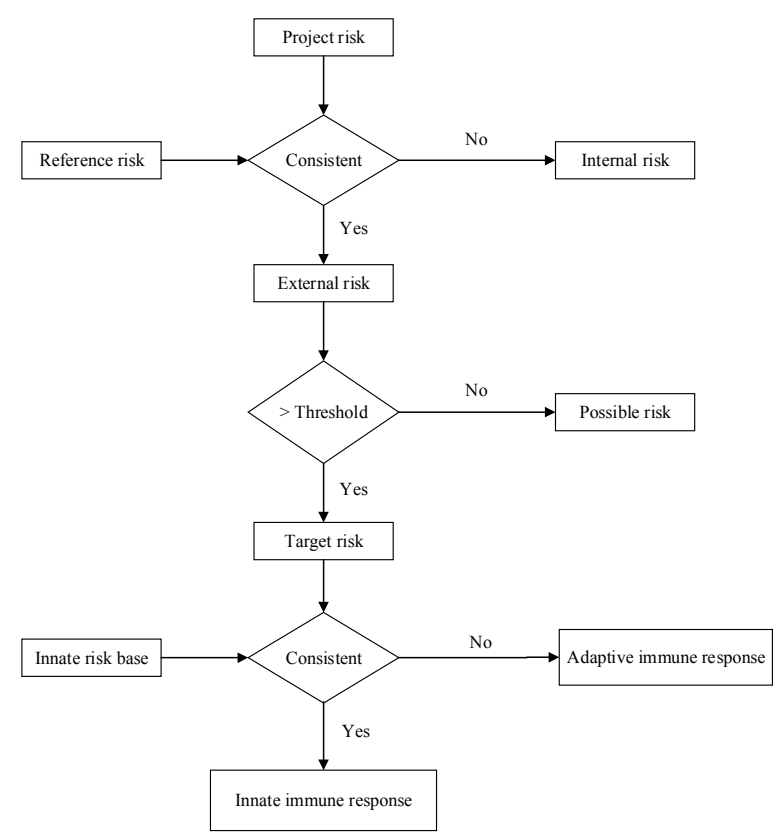

FIGURE I. THE RISK IMMUNE PROCESS

\section{INNATE IMMUNE RESPONSE MODEL}

The innate immune response model responds to regular innate risk based on CBR method. The model comprises of four parts. They are the description of project sets, the adjustment of weight, the evaluation of matching degree, and the selection of strategies, respectively.
The target project is defined as $\mathrm{T}=\left\{\mathrm{r}_{1}, \mathrm{r}_{2}, \cdots, \mathrm{r}_{\mathrm{m}}\right\}$, where $\mathrm{r}$ represents the risk indicators factorized from primary risk. Likewise, the reference project $i$ is $\left\{R_{i 1}, R_{i 2}, \cdots, R_{i n}\right\}$. The reference set $\mathrm{R}$ is expressed as the risk matrix.

$$
\mathrm{R}=\left[\begin{array}{cccc}
\mathrm{R}_{11} & \mathrm{R}_{12} & \cdots & \mathrm{R}_{1 \mathrm{n}} \\
\mathrm{R}_{21} & \mathrm{R}_{22} & \cdots & \mathrm{R}_{2 \mathrm{n}} \\
\vdots & \vdots & \vdots & \vdots \\
\mathrm{R}_{\mathrm{m} 3} & \mathrm{R}_{\mathrm{m} 2} & \cdots & \mathrm{R}_{\mathrm{mn}}
\end{array}\right]
$$

The initial weight for each risk indicator is the percentage of standard deviation. This paper sets time coefficient to adjust the initial weight of time-varying indicators. Other weights are revised accordingly to remain the sum of weights stable.

$$
\omega_{\mathrm{ij}}=\left\{\begin{array}{l}
\omega_{\mathrm{j}}^{0}\left(1+\mathrm{Y}_{\mathrm{i}} \varepsilon\right), \mathrm{j}=\mathrm{f}(\mathrm{t}) \\
\omega_{\mathrm{ij}_{\mathrm{x}}}^{0} \frac{1-\omega_{\mathrm{ij}}}{1-\omega_{\mathrm{j}}^{0}}, \mathrm{j}_{\mathrm{x}} \neq \mathrm{j}
\end{array}\right.
$$

Where $\omega_{j}^{0}$ represents the initial weight for a specific indicator $\mathrm{j}$ and $\omega_{\mathrm{ij}}$ is the ultimate weight.

The matching degree between the target project and reference one is a function of two risk indicators and its expression changes with the type of indicators. Because indicators are numeric or interval, three function expressions are given as below (Liu et al., 2013):

$$
\begin{aligned}
& \operatorname{mat}\left(\mathrm{p}_{\mathrm{i}}, \mathrm{q}_{\mathrm{j}}\right)=1-\frac{\left|\mathrm{q}_{\mathrm{j}}-\mathrm{p}_{\mathrm{i}}\right|}{\max \{\mathrm{p}, \mathrm{q}\}-\min \{\mathrm{p}, \mathrm{q}\}} \\
& \operatorname{mat}\left(\mathrm{p}_{\mathrm{i}},[\alpha, \beta]\right)=\frac{\int_{\alpha}^{\beta} \operatorname{mat}\left(\mathrm{p}_{\mathrm{i}}, \mathrm{x}\right) \mathrm{dx}}{\beta-\alpha} \\
& \operatorname{mat}\left(\left[\mathrm{a}_{1}, \mathrm{~b}_{1}\right],\left[\mathrm{a}_{2}, \mathrm{~b}_{2}\right]\right)=\frac{\int_{\mathrm{a}_{1}}^{\mathrm{b}_{1}} \int_{\mathrm{a}_{2}}^{\mathrm{b}_{2}} \operatorname{mat}(\mathrm{x}, \mathrm{y}) \mathrm{dydx}}{\left(\mathrm{b}_{2}-\mathrm{a}_{2}\right)\left(\mathrm{b}_{1}-\mathrm{a}_{1}\right)}
\end{aligned}
$$

This paper considers both the macro and micro matching degrees. The dummy variable $\delta$ is introduced to control matching degree. The final matching degree mat $\left(R_{i}, T\right)$ is designed for decision-making. Strategies of the optimal project with the highest ultimate matching degree are directly applied to reduce the risk of the target project. 


$$
\begin{gathered}
\delta=\left\{\begin{array}{cc}
1, & \frac{1}{\mathrm{X}} \sum_{\mathrm{j}=1}^{\mathrm{m}} \mathrm{x}_{\mathrm{j}} \succ \sigma_{1} \quad \text { and } \operatorname{mat}\left(\mathrm{R}_{\mathrm{ij}}, \mathrm{T}_{\mathrm{j}}\right) \geq \sigma_{2} \\
0, & \text { else }
\end{array}\right. \\
\operatorname{mat}\left(\mathrm{R}_{\mathrm{ij}}, \mathrm{T}_{\mathrm{j}}\right)=\sum_{\mathrm{j}=1}^{\mathrm{m}} \sigma \omega_{\mathrm{ij}} \operatorname{mat}\left(\mathrm{R}_{\mathrm{ij}}, \mathrm{T}_{\mathrm{j}}\right)
\end{gathered}
$$

\section{ADAPTIVE IMMUNE RESPONSE MODEL}

The adaptive immune response model is used to choose an ideal solution from reference projects. The original risk strategies are modified to reduce target risks. After obtaining comprehensive weights of risk indicators, the reference projects are finally ranked by TOPSIS method (Xiong, 2014).

Step1. Defining the reference projects and primary risks as $\mathrm{C}_{\mathrm{i}}(\mathrm{i}=1,2, \cdots, \mathrm{m})$ an $\mathrm{S}_{\mathrm{j}}(\mathrm{j}=1,2, \cdots, \mathrm{n})$, respectively. Standardize the numbers of risks indicators and define them as $\mathrm{a}_{\mathrm{ij}}(\mathrm{i}=1,2, \cdots, \mathrm{m} ; \mathrm{j}=1,2, \cdots, \mathrm{n})$.

Step2. Invite $\mathrm{k}$ engineering professors to mark the risk indicators. Assuming that the last professor's mark about $S_{j}$ is defined as $\mathrm{e}_{\mathrm{kj}}$, the subjective weight $\omega_{1 \mathrm{j}}$ of $\mathrm{S}_{\mathrm{j}}$ is computed by the equation (7).

$$
\omega_{1 j}=\frac{\mathrm{ke}_{\mathrm{j}}}{\sum_{\mathrm{j}=1}^{\mathrm{n}} \sum_{\mathrm{i}=1}^{\mathrm{d}} \mathrm{e}_{\mathrm{kj}}}
$$

Step3. The entropy method is used to calculate the objective weight $\omega_{2 j}$ of $S_{j}$ as the equation 8 shows.

$$
\omega_{2 j}=\frac{1+\sigma \sum_{i=1}^{m} a_{i j} \ln a_{i j}}{m+\sigma \sum_{j=1}^{n} \sum_{i=1}^{m} a_{i j} \ln a_{i j}}
$$

$$
\text { Where } \sigma \in \mathrm{N}^{+}, \sigma=(\ln n)^{-1}, \lim _{\mathrm{a}_{\mathrm{ij}} \rightarrow 0} \ln \mathrm{a}_{\mathrm{ij}}=0
$$

Step4. According to combination weighting method, the final weight $\omega_{j}$ of $S_{j}$ is given in the equation (9), where $\mathrm{p}, \mathrm{q}\left(\mathrm{p} \succ 0, \mathrm{q} \succ 0, \mathrm{p}^{2}+\mathrm{q}^{2}=1\right)$ is the ratio of $\omega_{1 j}$ and $\omega_{2 j} \cdot \mathrm{p}$ and $\mathrm{q}$ are computed with the maximum value principle.

$$
\omega_{j}=p \omega_{i j}+q \omega_{2 j}(j=1,2, \cdots, n)
$$

Step5. According to TOPSIS method, a new weighted normalized decision matrix $b_{i j}=a_{i j} \omega_{j}$ is constructed. Positive ideal $\mathrm{v}^{+}$and negative ideal $\mathrm{v}^{-}$solutions are identified:

$$
\begin{aligned}
& \mathrm{v}^{+}=\left\{\mathrm{b}_{1}^{+}, \mathrm{b}_{2}^{+}, \cdots, \mathrm{b}_{\mathrm{j}}^{+}\right\} \text {max values } \\
& \mathrm{v}^{-}=\left\{\mathrm{b}_{1}^{-}, \mathrm{b}_{2}^{-}, \cdots, \mathrm{b}_{\mathrm{j}}^{-}\right\} \text {max values }
\end{aligned}
$$

The following equations (11) and (12) are built to obtain the weighted Euclidean distance from the comprehensive risk indicators of the alternative projects to $\mathrm{d}^{+}$and $\mathrm{d}^{-}$:

$$
\begin{aligned}
& \gamma_{i}^{+}=\left[\sum_{j=1}^{n}\left(b_{i j}-b_{j}^{+}\right)^{2}\right]^{\frac{1}{2}} \\
& \gamma_{i}^{-}=\left[\sum_{j=1}^{n}\left(b_{i j}-b_{j}^{-}\right)^{2}\right]^{\frac{1}{2}}
\end{aligned}
$$

Finally, the approaching degree $\gamma_{i}^{*}$ of every project is computed by the equation (13), and the reference projects can be ranked according to $\gamma_{\mathrm{i}}^{*}$.

$$
\gamma_{i}^{*}=\frac{\gamma_{i}}{\gamma_{i}+\gamma_{i}^{+}}
$$

Step6. Choose the best reference project $\mathrm{R}$ which owes the maximum $\gamma_{i}^{*}$. The risk decisions in the project should be modified to adapt the target project $\mathrm{r}$. Define the risk and its response resources in $R$ and $r$ as $R_{i}, M_{i}$ and $r_{i}, M_{i}^{*}$.

$$
\mathrm{M}_{\mathrm{i}}^{*}=\frac{\mathrm{r}_{\mathrm{i}} \mathrm{M}_{\mathrm{i}}}{\mathrm{R}_{\mathrm{i}}}(\mathrm{i}=1,2, \cdots, \mathrm{n})
$$

\section{CASE STUdy}

Yiyang-Loudi Highway Project is a typical large government-invested large project. This paper used two risk immune response models to establish strategies.

Through risk recognition, we found 6 innate risk factors and 15 adaptive risk factors in this case. 8 safety experts assessed these risk factors and 6 reference projects by questionnaires. The project $\mathrm{i}$ was numbered $\mathrm{as}_{\mathrm{i}}$. The results are shown in table 2 . 
TABLE II. EXPERTS ASSESSMENT RESULTS

\begin{tabular}{|c|c|c|c|c|c|c|c|}
\hline Type & Factors & $\mathrm{C}_{1}$ & $\mathrm{C}_{2}$ & $\mathrm{C}_{3}$ & $\mathrm{C}_{4}$ & $\mathrm{C}_{5}$ & $\mathrm{C}_{6}$ \\
\hline \multirow{6}{*}{ Innate } & $\mathrm{R}_{1}$ & 60 & 87 & 85 & 62 & 77 & 72 \\
\hline & $\mathrm{R}_{2}$ & 90 & 75 & 93 & 62 & 72 & 83 \\
\hline & $\mathrm{R}_{3}$ & 80 & 72 & 89 & {$[86,90]$} & 91 & 66 \\
\hline & $\mathrm{R}_{4}$ & 71 & {$[80,84]$} & 84 & 81 & 82 & 88 \\
\hline & $\mathrm{R}_{5}$ & 94 & 60 & 73 & 72 & 64 & 60 \\
\hline & $\mathrm{R}_{6}$ & 78 & 85 & 62 & 60 & 87 & 90 \\
\hline \multirow{15}{*}{ Adaptive } & $\mathrm{S}_{1}$ & 76 & 70 & 64 & 57 & 73 & 66 \\
\hline & $\mathrm{S}_{2}$ & 68 & 70 & 70 & 65 & 68 & 71 \\
\hline & $\mathrm{S}_{3}$ & 91 & 87 & 95 & 92 & 82 & 86 \\
\hline & $\mathrm{S}_{4}$ & 78 & 69 & 72 & 68 & 75 & 60 \\
\hline & $\mathrm{S}_{5}$ & 71 & 82 & 88 & 66 & 68 & 85 \\
\hline & $\mathrm{S}_{6}$ & 79 & 82 & 81 & 78 & 82 & 83 \\
\hline & $\mathrm{S}_{7}$ & 85 & 88 & 86 & 80 & 86 & 83 \\
\hline & $\mathrm{S}_{8}$ & 78 & 76 & 81 & 71 & 75 & 80 \\
\hline & $\mathrm{S}_{9}$ & 78 & 81 & 73 & 82 & 72 & 80 \\
\hline & $\mathrm{S}_{10}$ & 80 & 76 & 82 & 75 & 81 & 72 \\
\hline & $\mathrm{S}_{11}$ & 82 & 62 & 71 & 67 & 75 & 69 \\
\hline & $\mathrm{S}_{12}$ & 79 & 81 & 69 & 61 & 68 & 74 \\
\hline & $\mathrm{S}_{13}$ & 77 & 77 & 70 & 72 & 80 & 71 \\
\hline & $\mathrm{S}_{14}$ & 80 & 78 & 88 & 79 & 87 & 82 \\
\hline & $\mathrm{S}_{15}$ & 93 & 84 & 83 & 92 & 90 & 88 \\
\hline
\end{tabular}

Table 3 shows innate immune results. This paper set the threshold $\sigma_{1}$ as $80 \%$ and $\sigma_{2}$ as $65 \%$. The dummy variable $\delta$ only turned 1 for project 3 and 5 . This paper directly uses risk strategies of project 3 as the best project to fend off innate risk in the highway project.

TABLE III. INNATE IMMUNE RESULTS

\begin{tabular}{ccccc}
\hline Project & $\begin{array}{c}\text { Matching } \\
\text { degree }\end{array}$ & $\sigma$ & $\delta$ & $\begin{array}{c}\text { Ultimate } \\
\text { matching } \\
\text { degree }\end{array}$ \\
\hline 1 & 0.448 & $100 \%$ & 0 & 0 \\
2 & 0.615 & $80 \%$ & 0 & 0 \\
3 & 0.709 & $100 \%$ & 1 & 0.709 \\
4 & 0.362 & $60 \%$ & 0 & 0 \\
5 & 0.687 & $80 \%$ & 1 & 0.687 \\
6 & 0.618 & $40 \%$ & 0 & 0 \\
\hline
\end{tabular}

Table 4 gives adaptive immune results. After normalization and weight assessment of 15 risk factors, the calculated positive and negative ideal solutions are presented. The 6 projects were ranked by the weighted Euclidean distance from risk indicators to ideal solutions. Finally, project 5 was selected as the best reference project. The strategies $\mathrm{M}^{*}$ of each risk were modified according to the ratio of risk values.
TABLE IV. ADAPTIVE IMMUNE RESULTS

\begin{tabular}{ccccccc}
\hline $\mathrm{C}_{\mathrm{i}}$ & $\mathrm{C}_{1}$ & $\mathrm{C}_{2}$ & $\mathrm{C}_{3}$ & $\mathrm{C}_{4}$ & $\mathrm{C}_{5}$ & $\mathrm{C}_{6}$ \\
\hline $\mathrm{V}^{+}$ & 0.515 & 0.664 & 0.686 & 0.861 & 0.472 & 0.714 \\
$\mathrm{~V}^{-}$ & 0.788 & 0.705 & 0.743 & 0.511 & 0.751 & 0.725 \\
$\mathrm{~V}^{*}$ & 0.605 & 0.515 & 0.520 & 0.373 & 0.614 & 0.504 \\
$\mathrm{Rank}$ & 2 & 4 & 3 & 6 & 1 & 5 \\
\hline $\mathrm{S}_{\mathrm{i}}$ & $\mathrm{S}_{1}$ & $\mathrm{~S}_{2}$ & $\mathrm{~S}_{3}$ & $\mathrm{~S}_{4}$ & $\mathrm{~S}_{5}$ & $\mathrm{~S}_{6}$ \\
\hline $\mathrm{r}_{\mathrm{i}} / \mathrm{R}_{\mathrm{i}}$ & 1.03 & 0.97 & 1.03 & 1.17 & 0.89 & 0.99 \\
$\mathrm{M}^{*}$ & $1.03 \mathrm{M}_{1}$ & $0.97 \mathrm{M}_{2}$ & $1.03 \mathrm{M}_{3}$ & $1.17 \mathrm{M}_{4}$ & $0.89 \mathrm{M}_{5}$ & $0.99 \mathrm{M}_{6}$ \\
\hline $\mathrm{S}_{\mathrm{i}}$ & $\mathrm{S}_{7}$ & $\mathrm{~S}_{8}$ & $\mathrm{~S}_{9}$ & $\mathrm{~S}_{10}$ & $\mathrm{~S}_{11}$ & $\mathrm{~S}_{12}$ \\
\hline $\mathrm{r}_{\mathrm{i}} / \mathrm{R}_{\mathrm{i}}$ & 1.01 & 1.00 & 0.90 & 1.08 & 1.10 & 0.95 \\
$\mathrm{M}^{*}$ & $1.01 \mathrm{M}_{7}$ & $\mathrm{M}_{8}$ & $0.90 \mathrm{M}_{9}$ & $1.08 \mathrm{M}_{10}$ & $1.10 \mathrm{M}_{11}$ & $0.95 \mathrm{M}_{12}$ \\
\hline $\mathrm{S}_{\mathrm{i}}$ & $\mathrm{S}_{13}$ & $\mathrm{~S}_{14}$ & $\mathrm{~S}_{15}$ & & & \\
\hline $\mathrm{r}_{\mathrm{i}} / \mathrm{R}_{\mathrm{i}}$ & 1.06 & 0.96 & 0.98 & & & \\
$\mathrm{M}^{*}$ & $1.06 \mathrm{M}_{13}$ & $0.96 \mathrm{M}_{14}$ & $0.98 \mathrm{M}_{15}$ & & & \\
\hline
\end{tabular}

\section{CONCLUSIONS}

This paper proposes the immune response model, including an innate immune response model and an adaptive immune response model to reduce different types of risks. The previous projects saved in the database are fully utilized to form risk response strategies. Finally, these models are successfully applied in the Yiyang-Loudi Highway Project.

Different from other research, this paper introduces the biological immune mechanism to decrease governmentinvested large projects risks. The artificial response includes innate immune response and adaptive immune response. Then relative models are specially constructed to prevent the immune risk comprehensively, conveniently and accurately.

There are some limitations of this paper. This paper only focuses on the static risks during a short-term period. Some fake risks may exceed the threshold and turn into the immune risk with the development of projects. Therefore, the risk immune response mechanism can be developed towards the dynamic direction in future research.

\section{REFERENCES}

[1] Eybpoosh, M., Dikmen, I., and Birgonul, M. T. (2011). Identification of risk paths in international construction projects using structural equation modeling. Journal of Construction Engineering and Management, 137(12), 1164-1175.

[2] Hamzaoui, F., Taillandier, F., Mehdizadeh, R., Breysse, D., and Allal, A. (2015). Evolutive risk breakdown structure for managing construction project risks: application to a railway project in algeria. Revue Franãßaise De GãCnie Civil, 19(2), 238-262.

[3] Ebrat, M., and Ghodsi, R. (2014). Construction project risk assessment by using adaptive-network-based fuzzy inference system: an empirical study. Ksce Journal of Civil Engineering, 18(5), 1213-1227. 
[4] Zhao, X., Hwang, B. G., and Gao, Y. (2016). A fuzzy synthetic evaluation approach for risk assessment: a case of singapore's green projects. Journal of Cleaner Production, 115, 203-213.

[5] Kwan, T. W., and Leung, H. K. N. (2011). A risk management methodology for project risk dependencies. IEEE Transactions on Software Engineering, 37(5), 635-648.

[6] Yim, R., Castaneda, J., Doolen, T., Tumer, I., and Malak, R. (2015). A study of the impact of project classification on project risk indicators. International Journal of Project Management, 33(4), 863-876.

[7] Geraldi, J. G. (2008). The balance between order and chaos in multiproject firms: a conceptual model. International Journal of Project Management, 26(4), 348-356.

[8] Koppenjan, J., Veeneman, W., Voort, H. V. D., Heuvelhof, E. T., and Leijten, M. (2011). Competing management approaches in large engineering projects: the dutch randstadrail project. International Journal of Project Management, 29(6), 740-750.

[9] Lenfle, Sylvain and Loch, Christoph. (2010). Lost Roots: How Project Management Came to Emphasize Control Over Flexibility and Novelty. California Management Review. 53.

[10] Rao, T., and Schoenherr, T. (2011). Assessing and managing risks using the supply chain risk management process (scrmp). Supply Chain Management, 16(6), 474-483.

[11] Fang, C., and Marle, F. (2012). A simulation-based risk network model for decision support in project risk management. Decision Support Systems, 52(3), 635-644.

[12] Osipova, E., and Eriksson, P. E. (2013). Balancing control and flexibility in joint risk management: lessons learned from two construction projects. International Journal of Project Management, 31(3), 391-399.

[13] Liu D Y, Zhu C F, Ding W. (2013). Research on Emergency Supply Demand Forecast Methods Based on Case Reasoning. Journal of Lanzhou Jiaotong University, 32(4), 120-123.

[14] Wei Xiong(2014). Operations Reaserch 3nd. China Machine Press,308343 